\title{
Laicidade e Conselho Federal de Psicologia: Dinâmica Institucional e Profissional em Perspectiva Jurídica
}

\author{
Roger Raupp Rios \\ UniRitter, RS, Brasil. \\ Rodrigo da Silva \\ UniRitter, RS, Brasil.
}

\author{
Alice Hertzog Resadori \\ UFRGS, RS, Brasil. \\ Daniel Martins Vidor \\ UniRitter, RS, Brasil.
}

\begin{abstract}
Resumo: Apesar de vivermos em um estado laico, têm crescido no Brasil iniciativas pela inclusão de conteúdos religiosos em medidas estatais e até mesmo na organização do Estado. Estes movimentos permeiam inclusive os debates com relação à atuação de conselhos de fiscalização profissional, como é o caso do Conselho Federal de Psicologia (CFP). Delicado e desafiador, tal contexto exige clareza intelectual e postura política democrática. Assim, este artigo busca examinar os fundamentos e o modelo da laicidade constitucional no Brasil e refletir sobre as consequências desse modelo para a vida institucional e a fiscalização profissional do CFP, contribuindo, portanto, para ampliar o debate acadêmico sobre o tema. Ademais, a presente pesquisa, de caráter teórico, se mostra socialmente relevante na medida em que a adoção de posturas democráticas nos debates públicos atuais como a "cura gay", a "ideologia de gênero", as políticas públicas de saúde e o credenciamento de cursos de graduação em Psicologia perpassa pela compreensão do conceito de laicidade e da sua aplicação ao CFP.

Palavras-chave: Laicidade Constitucional, Igualdade, Liberdade de Religião, Fiscalização Profissional, Conselho Federal de Psicologia.
\end{abstract}

\section{Laicity and Federal Council of Psychology: institutional and professional dynamics in a legal perspective}

\begin{abstract}
Although we live in a secular state, initiatives for the inclusion of religious content in state measures and even in the state organization have been growing in Brazil. These movements permeate even the debates regarding the activity of professional supervisory boards, such as the Federal Council of Psychology (CFP). Delicate and challenging, this context requires intellectual clarity and democratic political stance. Therefore, this article aims to examine the fundamentals and the constitutional laicity model in Brazil and to reflect on the consequences of this model for the institutional life and the professional supervision of the CFP, contributing thus to expand the academic debate on the theme. Moreover, this theoretical research is socially relevant because of the fact that the adoption of democratic attitudes in the current public debate as the "gay cure", "gender ideology", public health policies and accreditation of degree courses in psychology pervades the understanding of the concept of laicity and its application to the CFP. Keywords: Constitutional Secularism, Equality, Freedom of Religion, Professional Supervision, Federal Council of Psychology.
\end{abstract}




\title{
Laicidad y Consejo Federal de Psicología: dinámica institucional y profesional en perspectiva jurídica
}

\begin{abstract}
Resumen: A pesar de que vivimos en un estado laico, han crecido iniciativas en Brasil en el sentido de incluir contenido religioso en las medidas estatales e incluso en la organización estatal. Estos movimientos permean inclusive los debates con respecto a la actuación de los consejos de supervisión de profesionales, como el Consejo Federal de Psicología (CFP). Delicado y difícil, este contexto requiere claridad intelectual y postura política democrática. Por lo tanto, este artículo tiene por objeto examinar los fundamentos y el modelo de laicidad constitucional en Brasil y reflexionar sobre las consecuencias de este modelo para la vida institucional y la supervisión profesional del CFP, lo que contribuye a ampliar el debate académico sobre el tema. Además, la presente investigación, de carácter teórico, se muestra socialmente relevante en la medida en que la adopción de actitudes democráticas en los debates públicos actuales como la "cura gay”, "ideología de género", políticas de salud pública y acreditación de cursos de pregrado de psicología, pasa por la comprensión del concepto de laicidad y su aplicación al CFP.

Palabras clave: Laicidad Constitucional, Igualdad, Libertad de Religión, Supervisión Profesional, Consejo Federal de Psicología.
\end{abstract}

\section{Introdução}

No Brasil de nossos dias, crescem iniciativas pela inclusão de conteúdos religiosos em medidas estatais e até mesmo na organização do Estado. Reforma constitucional (Brasil, 2011a), legislação (Brasil, 2011b; Duarte, 2009), formulação e execução de políticas públicas (Pereira, 2013) têm sido mais e mais arena de pressão por indivíduos e grupos cujo objetivo é a inserção de conteúdos religiosos na vida estatal (CUNHA, 2012). Estes movimentos permeiam inclusive os debates com relação à atuação de conselhos de fiscalização profissional, como é o caso do Conselho Federal de Psicologia (CFP).

Delicado e desafiador, tal contexto exige clareza intelectual e postura política democrática. Daí o percurso deste artigo: examinar os fundamentos e o modelo da laicidade constitucional no Brasil (primeira parte) ${ }^{1} \mathrm{e}$ refletir sobre as consequências desse modelo para a vida institucional e a fiscalização profissional do Conselho Federal de Psicologia (segunda parte).

A presente pesquisa, de caráter teórico e do tipo qualitativa com a coleta de dados bibliográficos, além de ampliar o debate acadêmico sobre o tema, se mostra socialmente relevante na medida em que a adoção de posturas democráticas nos debates públicos atu- ais como a "cura gay", "ideologia de gênero", políticas públicas de saúde e credenciamento de cursos de graduação em Psicologia perpassa pela compreensão do conceito de laicidade e da sua aplicação ao CFP.

\section{Laicidade no Direito Constitucional brasileiro}

Na primeira parte deste artigo será examinado o conceito de laicidade, seus fundamentos, bem como o modelo de laicidade constitucional adotado pelo Estado brasileiro.

\section{$O$ conceito e os fundamentos da laicidade na Constituição de 1988}

Esta seção trata dos fundamentos constitucionais da laicidade, considerados a partir de ideais democráticos presentes no constitucionalismo ocidental. Sem qualquer menosprezo a outras experiências, muito menos às relações entre determinados modelos de laicidade e a ideia ocidental de modernidade (Cady, \& Hurd, 2010; Wohlrab-Sahr, \& Burchardt, 2012), com implicações colonialistas (Keane, 2000;

\footnotetext{
${ }^{1}$ Nessa primeira seção, é reproduzido parcial e sintetizadamente estudo já realizado sobre os fundamentos e modelos da laicidade constitucional brasileira (Rios, 2015).
} 
Morin, \& Ramadan, 2014; Sabet, 2008), centra-se a atenção nestes elementos a partir do debate brasileiro contemporâneo, em particular à experiência democrática iniciada desde a derrocada da ditadura militar (1964-1985) e ao texto constitucional de 1988.

A laicidade é uma resposta ao desafio da pluralidade religiosa no mundo moderno e contemporâneo. Politicamente, ela emerge das guerras religiosas e da necessidade de encontrar um modo de convívio possível e pacífico, descartadas as alternativas da opressão de minorias religiosas e da eliminação da diversidade religiosa (Canotilho, 2003); ela é mais um método que um conteúdo, diz Bobbio (1999), é uma condição para a convivência de todas as possíveis culturas. Juridicamente, a laicidade engendrará diferentes arranjos constitucionais ${ }^{2}$, destacando-se, na experiência ocidental, os modelos da neutralidade religiosa e da pluriconfessionalidade.

De fato, as religiões colocam desafios ao convívio democrático e plural quando pretendem ser abrangentes, fundamentalistas ou integristas e proselitistas (Lopes, \& Vilhena, 2013). Isto porque (1) ao requerem que seus adeptos sigam sua doutrina em todas as dimensões de suas vidas, sobrepondo seus deveres morais religiosos àqueles decorrentes da participação de seus seguidores na comunidade política nacional, (2) ao pretenderem estabelecer conteúdos indiscutíveis, vinculadores de todas as dimensões da vida de seus fiéis e (3) ao fazerem da ampliação de seu grupo de seguidores um objetivo fundamental, as religiões entram em rota de colisão com o pluralismo e a diversidade, cujo pressuposto é precisamente o convívio simultâneo e não excludente de diferentes visões de mundo, decorrentes ou não de convicções religiosas.

Exatamente por atentar especialmente à importância do pluralismo e da diversidade, a laicidade apresenta-se como o arranjo político-institucional e a configuração jurídico-constitucional mais apropriados à proteção das liberdades de pensamento, de opinião e de crença. Com efeito, a laicidade revela-se princípio de organização estatal que possibilita, simultaneamente, a proteção em face do perigo de intervenção e manipulação estatal no âmbito religioso e a defesa de indivíduos e de grupos diante da tentação de maiorias que almejem impor suas convicções religiosas sobre os demais por meio do processo político.
Nunca é demais salientar a relação entre a afirmação da liberdade religiosa e as proibições constitucionais de interferência estatal nas religiões e de intromissão de argumentos religiosos na vida estatal. Nesse campo, não há oposição entre laicidade e liberdade religiosa (Sarmento, 2008). Ao contrário, a laicidade tem dentre seus conteúdos essenciais a esfera de liberdade, em favor de indivíduos e grupos, de tomada de posição diante do fenômeno religioso como bem entenderem, adotando ou rejeitando crenças religiosas, onde se inclui evidentemente o ateísmo. A laicidade cumpre a função, portanto, de garantia institucional para a liberdade religiosa, cujo alcance inclui não somente a esfera pública, como também as relações entre privados, o que pode ser percebido pelo fenômeno do assédio religioso no ambiente de trabalho (Lorea, 2008).

A relação entre laicidade e igualdade é também direta e inestimável. A laicidade, como princípio de organização da vida estatal na democracia, leva a sério a igualdade de todos os cidadãos. Ela impede vantagens ou prejuízos na esfera estatal a indivíduos e grupos por motivo de crença religiosa. Afastando qualquer consideração religiosa do debate político estatal, ela viabiliza a igualdade de todos diante do Estado, ao tornar argumentos religiosos não somente irrelevantes no processo de deliberação estatal, como também proscrevê-los.

Na laicidade, a irrelevância e o afastamento de conteúdos religiosos da esfera política estatal decorrem dos pressupostos necessários para o convívio democrático em sociedades plurais, cujo teor não se coaduna à dinâmica de argumentos de fé. Em sociedades democráticas, dada a valorização e o respeito ao pluralismo, os processos de tomada de decisão política e a execução das políticas públicas necessitam ser acessíveis a todos os cidadãos, tanto pelos instrumentos de participação disponíveis, quanto pela possibilidade de compreensão e debate público das razões invocadas no processo político. Argumentos religiosos, por definição, emanam de revelação divina, diante dos quais os fiéis devem obediência (Vier, 1984a); para os crentes, a fé é, ao fim e ao cabo, a luz que tudo deve iluminar (Vier, 1984b) e, mesmo no terreno das ciências que se debruçam sobre as realidades terrestres, religiosos tem na fé naquilo

${ }^{2}$ Sobre os diversos modelos de laicidade presentes na América Latina, ver Oro e Ureta (2007). 
que foi revelado por Deus o teste final para a correção do método científico (Vier, 1984b). Argumentos religiosos, ao veicular certos conteúdos e defender certas posições, fundam-se na obediência àquilo que se acredita revelado pela divindade, não na razão humana que busca apreender e compreender a realidade, de modo esforçado, metódico, humilde e aberto à dúvida e à contestação.

Daí não haver, conforme postula a laicidade, espaço para argumentos religiosos no processo de deliberação política estatal. Assim não fosse, estariam feridas de morte a liberdade religiosa, a igualdade de todos os cidadãos, o pluralismo e a diversidade. Deliberações majoritárias (como no caso do processo legislativo) e decisões jurídicas tomadas de acordo com o processo constitucional (como acontece na interpretação das leis pelo Judiciário) só respeitam a liberdade religiosa de todos, a igualdade perante a lei, o pluralismo político e a diversidade, se produzidas com base em argumentos racionais, acessíveis à compreensão e ao debate de todos os cidadãos. Adotar uma política pública com fundamento na crença religiosa de alguns (ainda que amplamente majoritários) exclui do procedimento decisório todos os demais que não compartilham da mesma fé, criando desigualdade entre os cidadãos perante o Estado em virtude de crença religiosa e ferindo de morte a própria liberdade religiosa.

Argumentos religiosos são, por definição, incompatíveis com tais imperativos democráticos, dada sua origem na revelação divina. Para quem professa esta ou aquela religião, não há espaço para compromissos em matéria de fé. Não há negociação diante da vontade divina, pois neste terreno qualquer composição implica contrariedade aos desígnios divinos e traição àquilo que se considera a única e indiscutível verdade. A democracia pluralista, ao contrário, é o domínio da diversidade de opiniões e crenças, cujo convívio requer composição, negociação e conciliação diante de pontos de vista divergentes, numa dinâmica aberta a tomada de decisões mutáveis ao longo do tempo. Mesmo os mais caros conteúdos políticos e jurídicos, sem dúvida fora do espaço da negociação e da deliberação políticas, são frutos de decisões humanas, historicamente construídas. Disposições constitucionais que expressam valores merecedores de especialíssima proteção constitucional (como, por exemplo, a igual dignidade de todos os seres humanos e a proibição da tortura), não deixam de ser decisões políticas humanas fundamentais.

Como visto, dentre os fundamentos da laicidade encontram-se os direitos fundamentais de liberdade e de igualdade, como também o pluralismo, compreendido como princípio de organização do Estado que se contrapõe à concentração e à unificação do poder (Bobbio, Mateucci, \& Pasquino, 1986). Ao lado deles, aparece a diversidade como outro dos fundamentos da laicidade, entendida como multiplicidade de convicções religiosas (onde se insere, não é demais lembrar, a ausência de crença religiosa). A diversidade religiosa, compreendida como um dado da realidade positivamente considerado na democracia brasileira, apresenta-se como um verdadeiro bem jurídico-constitucional, do mesmo modo como as diversidades étnica, regional e cultural, explicitamente listadas no texto constitucional (respectivamente, nos artigos 215, inciso V, e 216-A, p. 1, inciso I).

Conectada de modo umbilical a direitos fundamentais (liberdade religiosa e igualdade de todos), ao pluralismo como princípio político basilar e à diversidade religiosa como bem constitucional, a laicidade apresenta diversas dimensões. A formulação de um conceito, na medida do possível, deve abarcá-los da melhor forma. O termo, datado de 1871, cujo conceito ora se investiga, surge como neologismo francês no seio do republicanismo da liberdade de opinião, num contexto de marcada oposição à monarquia e à vontade divina como fundamentos e organização da sociedade política (Oro, 2008).

No debate sobre os elementos essenciais ao conceito $^{3}$, destacam-se: (a) a legitimidade das instituições políticas radicada na soberania popular, não mais em conteúdos religiosos (Blancarte, 2008); (b) a "relação chave" com os direitos fundamentais de liberdade religiosa, de consciência e de igualdade (Huaco, 2008) e (c) tratar-se de instrumento para a gestão das liberdades e direitos de todos os cidadãos (Blancarte, 2008).

Daí a formulação jurídica da laicidade a partir dos textos internacionais protetivos de direitos humanos, quando estes garantem as liberdades de pensamento, de consciência e de religião, como também quando

\footnotetext{
${ }^{3}$ Um panorama acerca do conceito jurídico da laicidade e sua caracterização como norma constitucional tipo princípio são fornecidos por Zyblersztajn (2012).
} 
afirmam a igualdade de todos, a não discriminação e o combate à intolerância ${ }^{4}$.

\section{Neutralidade e pluriconfessionalidade laicas}

Assentados os fundamentos da laicidade e delineado o conceito constitucional de laicidade, é preciso examinar qual o modelo de laicidade decorrente do arranjo institucional que resultou na Constituição de 1988 (Brasil, 2008a). Isso colocado, vale salientar, por oposição, aquilo que a laicidade pluriconfessional não é, nem admite, diante dos desafios impostos à democracia por iniciativas políticas advindas de grupos religiosos.

A combinação dos direitos de liberdade e de igualdade, do valor político do pluralismo e da diversidade religiosa como dado da realidade constitucionalmente valorizado dá ensejo a vários arranjos institucionais possíveis. Tanto que, ao longo da história do Brasil, tivemos desde confessionalidade tolerante com religiões não oficiais (a Constituição do Império adotava o catolicismo como religião oficial, mas tolerava culto privado de outras denominações) até a mais forte separação entre Estado e religião (a Constituição de 1891 proibiu a participação política de religiosos, reconheceu exclusivamente o casamento civil o e caráter leigo do ensino público e secularizou a administração dos cemitérios). A Constituição imperial, definitivamente, não era laica: não somente professava religião oficial, como também excluía de cargos públicos não católicos; a primeira constituição republicana, aquela onde a laicidade foi mais pronunciada, não era laicista, por não trazer as notas de anticlericalismo ou hostilidade à religiosidade coletiva (Huaco, 2008).

Tendo presente a compreensão constitucional do Estado laico, qual o modelo de laicidade da Constituição de 1988? Ainda que o processo constituinte tenha registrado movimentação e tensão religiosas diante de vários temas (Pierucci, \& Prandi, 1996; Pinheiro, 2008), o resultado do processo constituinte foi a afirmação do Estado laico, por meio da separação institucional entre Estado e religião, com possibilidade de cooperação em determinadas áreas entre o Estado e as igrejas (o inciso I do artigo 19 veda a vinculação do Estado à religião, "ressalvada, na forma da lei, a colaboração de interesse público"). Este arranjo de "separação com cooperação", acrescido (1) da presença do ensino religioso, de caráter facultativo, nos estabelecimentos públicos (art. 201, p. $1^{\circ}$ ), (2) da escusa do serviço militar por crença religiosa (art. 143, p. $1^{\circ}$ ), (3) da possibilidade de efeitos civis do casamento religioso (art. 226, p. $2^{\circ}$ ), (4) da possibilidade de assistência religiosa nas entidades civis e militares de internação coletiva (art. 5º, VII) e (5) da imunidade tributária a templos de qualquer culto (art. 150, VI, b), configura o modelo de laicidade denominado pluriconfessional.

A laicidade pluriconfessional contrasta com o modelo de laicidade como neutralidade religiosa. Neste não se reconhece qualquer caráter primordial ao fato religioso, sendo inclusive um dado a ser evitado no espaço público estatal, dada sua potencial e irresolúvel conflitividade. Em vez de preocupar-se com a expressão pública e plural das crenças, até mesmo as apoiando (como faz a pluriconfessionalidade), a laicidade da neutralidade almeja coibir pretensões de ascensão ao poder estatal por parte de grupos religiosos, característica que a faz receber pecha de mecanismo de opressão estatal diante da diversidade religiosa (Diniz, 2006). A laicidade como neutralidade, com efeito, traz consigo sempre o perigo de esmaecer realidades históricas e políticas nas quais determinadas tradições religiosas acabam deixando marcas nas definições de nacionalidade e de espaço público (Giumbelli, 2012).

Este desenho institucional coloca o Brasil no campo da laicidade, uma vez que seus elementos fundamentais estão presentes: (a) garantia dos direitos fundamentais de liberdade e de igualdade para todos, sem depender de crença religiosa; (b) neutralidade quanto ao dado religioso do ponto de vista institucional, pela impossibilidade de argumentos de fé em processos de deliberação democrática majoritária e na configuração e execução das políticas públicas, ainda que admitida a cooperação de interesse público e (c) ausência de hostilidade a indivíduos e grupos em virtude de crença religiosa, conjugada com mecanismos de convivência e de valorização da diversidade religiosa.

\footnotetext{
${ }^{4}$ Ver, neste sentido, a Declaração Universal de Direitos Humanos (art. 18), o Pacto Internacional de Direitos Civis e Políticos (art. 18), a Convenção Americana de Direitos Humanos (art. 12), a Declaração sobre a Eliminação de todas as Formas de Intolerância e Discriminação fundadas na Religião ou nas Convicções (art. 1) e a Convenção Interamericana contra todas as formas de Discriminação e Intolerância (art. 1).
} 
Assim, por exemplo, a laicidade da neutralidade, ao elaborar as políticas públicas, não levará em consideração vestimentas ou adereços com significado religioso, como ocorre com a polêmica relativa à proibição do uso de véu por estudantes muçulmanas na França, ao passo que a laicidade pluriconfessional, ao projetar e construir um aeroporto, alocará um espaço de oração adaptado a diversos símbolos religiosos, pertencentes a comunidades de fé variadas. Com relação à colaboração na execução das políticas públicas, a laicidade pluriconfessional a prevê explicitamente, como faz a Constituição de 1988 (Brasil, 1988a), em seu artigo 19 ("ressalvada, na forma da lei, a colaboração de interesse público" - como ocorre com a prestação da saúde pública e a atuação de Santas Casas de Misericórdia), enquanto a laicidade como neutralidade não admite tal modalidade de interação.

\section{O que a democracia laica pluriconfessional não é}

Considerando a realidade brasileira, o modelo de laicidade pluriconfessional definido constitucionalmente e as relações históricas entre política, cultura e religião, num quadro em que déficits educacionais perduram e onde há intensa utilização de comunicação de massa por igrejas não é demais salientar que:

(a) a laicidade pluriconfessional não é democracia das maiorias ou dos consensos religiosos, por não haver garantia de liberdade, igualdade, pluralismo e diversidade em sociedades políticas regidas por conteúdos religiosos; (b) a laicidade pluriconfessional não admite que atos estatais tenham como fundamento crenças religiosas, sob pena da anulação da liberdade religiosa de todos os submetidos, sejam ateus, agnósticos ou religiosos, acompanhada da opressão da maioria religiosa sobre todos os demais; (c) a laicidade pluriconfessional não se confunde com possibilidade nem abertura do sistema político à imposição da fé de determinado grupo, pois estariam violadas não só a igualdade de todos perante a lei, como também a dignidade humana, dado que os vencidos seriam transformados em objeto da deliberação alheia, por convicção inacessível à compreensão de quem não compartilhar da fé vencedora; (d) a laicidade pluriconfessional não é permissão para o fatiamento das políticas públicas entre as diversas denominações religiosas, mesmo que entre estas estejam presentes tal vontade e projeto; (e) a laicidade pluriconfessional não é regime de condomínio religioso do poder político estatal, nem de coabitação de denominações religiosas nos poderes públicos ou na Administração; (f) a laicidade pluriconfessional não significa a inserção, no conteúdo do princípio democrático, de qualquer dever de deferência a valores professados por comunidades religiosas majoritárias ou não, na medida em que o respeito aos fundamentos da laicidade (liberdade religiosa, igualdade sem discriminação por motivo de crença religiosa, pluralismo social e diversidade) não depende de fé religiosa, sendo perfeitamente observados em comunidades políticas onde eventualmente cidadãos ateus ou agnósticos sejam amplamente majoritários.

Todas estas advertências são necessárias para que não se corra o grave risco de confundir-se o direito de participação política de cidadãos que professam publicamente sua fé, direito aberto a todos, independentemente de crença religiosa, com projetos de poder político estatal que se valem da força persuasiva de conteúdos religiosos, buscando mobilizar maiorias eventuais. A participação política de tais cidadãos, com ou sem motivação religiosa no seu foro íntimo, não tem outra alternativa democrática senão a defesa de suas posições por meio de argumentos racionais, aferíveis e discutíveis por todos os demais membros da sociedade política.

\section{A Laicidade e o Conselho Federal de Psicologia}

Neste ponto serão analisadas as consequências do modelo de laicidade adotada pelo Estado brasileiro para a vida institucional e para a fiscalização profissional do Conselho Federal de Psicologia.

\section{Natureza jurídica e regime jurídico aplicável ao CFP}

Compreendido o conteúdo da laicidade pluriconfessional, passa-se a analisar como este princípio se relaciona com o Conselho Federal de Psicologia. Para tanto, importante de início identificar sua natureza jurídica e sujeição ao regime jurídico da Administração Pública, uma vez que dessa relação decorrem relevantes e decisivas consequências jurídicas.

O livre exercício de trabalhos, ofícios e profissões é garantido pelo artigo $5^{\circ}$, XIII da Constituição da República Federativa do Brasil, desde que sejam 
atendidas as qualificações profissionais previstas em lei (Brasil, 1988). Ao prever a necessidade de que sejam observados parâmetros de qualificação técnica para o exercício profissional, o legislador constituinte buscou defender a sociedade de práticas profissionais antiéticas, de atividades realizadas por leigos (nos casos em que é necessária qualificação) ou mesmo por profissionais habilitados, mas que não cumprem com as condutas previstas para determinada profissão.

A competência para legislar sobre as qualificações exigidas para cada profissão, bem como para fiscalizar seu cumprimento, é privativa da União, nos termos dos artigos 21 e 22 da Constituição (Brasil, 1988a). Para tanto, foram criados conselhos de fiscalização profissional, que, apesar de deterem personalidade jurídica de direito privado (Brasil, 1998), cumprem verdadeiro serviço público, submetendo-se assim ao regime jurídico de direito público, de observância obrigatória no exercício do poder de polícia, de arrecadação mediante taxas, de fiscalização profissional quanto ao exercício da profissão e também quanto à dinâmica democrática de funcionamento do órgão ${ }^{5}$. Apesar de sua natureza pública, estes conselhos não atuam dentro da estrutura estatal, dada sua personalidade jurídica destacada de outros órgãos da Administração, fazendo parte da Administração Indireta, como autarquias.

Neste quadro, o CFP foi criado pela Lei $\mathrm{n}^{\circ} 5.766$, de 1971, com a finalidade de orientar, disciplinar e fiscalizar o exercício da profissão de psicólogo e zelar pela fiel observância dos princípios da ética e da disciplina da classe. (Brasil, 1971). Para alcançar estes objetivos, exerce poder de polícia administrativa sobre os profissionais fiscalizados, devendo verificar eventuais situações contrárias às normas e ao interesse público e aplicar as penalidades cabíveis. Ou seja, desempenha atividades administrativas tipicamente estatais.

As autarquias, como é o caso do CFP, mais do que atuar em colaboração com o Estado, agem como um "braço" estatal; portanto, estão sujeitas a todos os preceitos constitucionais dirigidos ao Estado. Esse dado é importância capital na presente reflexão, pois conduz à conclusão insofismável quanto à incidência inafastável da laicidade na vida institucional do Conselho.
Nessa linha, afirma-se também a pertinência do CFP às prerrogativas e às restrições inerentes ao regime jurídico-administrativo (Di Pietro, 2014), em especial aos deveres de respeito aos princípios constitucionais da Administração Pública, como a supremacia do interesse público, a legalidade, a impessoalidade, a moralidade, a publicidade e a eficiência (artigo 37 da Constituição), assim como aos princípios da finalidade, motivação, razoabilidade, proporcionalidade, ampla defesa, contraditório, segurança jurídica e interesse público, conforme a Lei de Processo Administrativo Federal, Lei no 9.784 (Brasil, 1999).

A submissão do Conselho Federal de Psicologia à laicidade se relaciona especialmente a três princípios da Administração Pública, que merecem, portanto, destaque: a supremacia do interesse público, a legalidade e a impessoalidade.

O princípio da legalidade é compreendido como o princípio basilar do regime jurídico-administrativo, na medida em que traduz juridicamente a submissão de quem exerce o poder administrativo a um quadro normativo elaborado, formal e materialmente, segundo os princípios constitucionais formais e materiais, em especial ao interesse público, à possibilidade de compreensão e debate dos assuntos públicos por todos os cidadãos, independentemente de fé religiosa, bem como à prestação de contas por parte do aplicador da lei de sua observância a tais ditames. Tal a ideia resumida na advertência segundo a qual a atuação dos entes administrativos deve ficar adstrita ao que determina a lei, não podendo fazer senão o que ela determina (Mello, 2012).

Assim, o princípio da legalidade ao qual a atuação do CFP está adstrita carrega consigo o dever de observância à laicidade constitucional, pelo que tanto a formulação parlamentar da lei, quanto sua aplicação pelo Conselho, proscrevem a inclusão de conteúdos religiosos ou a omissão de fiscalização disciplinar em face de sua invocação como expressão de atividade profissional. Isso tanto em decorrência do mandamento constitucional da laicidade, conforme acima explicitado, como também porque resultaria em determinar ou aceitar atividade estatal fundada em preceitos de impossível verificação, fis-

\footnotetext{
${ }^{5}$ No que tange ao tipo de ente da administração indireta, o STF, ao julgar os Mandados de Segurança no 22643 e 21797, já firmou entendimento no sentido de que os conselhos de fiscalização profissional são autarquias, ou seja, são pessoas jurídicas de direito público, criadas por lei, com autonomia administrativa e financeira, que desempenham atividades típicas do Estado (Mello, 2012).
} 
calização e debate público, inviabilizando a função constitucional da legalidade na democracia laica e deixando espaço, inclusive, para desmandos e afastamento do interesse público, que é garantir aos que buscam serviço psicológico a certeza e a segurança de que a fiscalização pelo CFP assegura que o conhecimento científico e técnico no exercício profissional estejam presentes.

Nesse contexto, acaso o CFP admitisse conteúdos religiosos no exercício profissional, a legalidade acabaria esvaziada, comprometendo a finalidade pública e institucional do CFP, sem falar na impossibilidade daí resultante de motivação de ato administrativo de fiscalização da profissão, dado que argumentos de fé são por definição insindicáveis racionalmente, senão àqueles que professam eventualmente a mesma confissão religiosa.

Comprometidas a finalidade e a atuação fiscalizatória da profissão, outro princípio constitucional a que se submete o CFP cujo conteúdo estaria esvaziado é o da eficiência, na medida em que este requer que a ação administrativa esteja orientada para a legalidade, empregando-se os melhores meios e recursos disponíveis. Essa tarefa, contudo, ficaria obstaculizada sem o respeito à laicidade constitucional, pois o dever de fiscalização visando ao interesse público esbarraria sempre em questões de fé. Tudo isso sem falar nos riscos de desvio de finalidade decorrentes da admissão de conteúdos de fé na atuação administrativa.

No que tange ao princípio da impessoalidade, este determina que a Administração Pública deve tratar todos os administrados sem discriminações, perseguições ou favoritismos. "Simpatias ou animosidades pessoais, políticas ou ideológicas não podem interferir na atuação administrativa e muito menos interesses sectários, de facções ou grupos de qualquer espécie" (Mello, 2012).

Conforme preceitua o art. $5^{\circ}$, XIII (Brasil, 1988), a fiscalização profissional deve se dar de acordo com a qualificação prevista em lei. A atuação profissional fundamentada em preceitos religiosos é embasada em qualificações de outro cunho que não legal, não havendo, portanto, como o Conselho fiscalizar se a atuação profissional religiosa está sendo ou não desempenhada de forma adequada. Daí que tal circunstância, que acabaria por permitir que o exercício da profissão se desse sem a possibilidade de controle e fiscalização de práticas profissionais psi- cológicas, seria admitir o tratamento diferenciado a determinado grupo de profissionais, que se tornaria, nessa medida, imune à fiscalização, violando o princípio da impessoalidade.

Há que se destacar as consequências do princípio da supremacia do interesse público, quanto à dinâmica institucional da entidade. Ele determina à Administração Pública que cumpra as suas finalidades de forma a alcançar o interesse da coletividade acima de interesses privados. (Mello, 2012). Deste princípio, deriva também a obrigação de os sujeitos da Administração Pública buscarem "o atendimento do interesse alheio, qual seja, o da coletividade, e não o interesse de seu próprio organismo, qua tale considerado, e muito menos o dos agentes estatais" (Mello, 2012, p. 102).

Como já visto, a finalidade do CFP é de orientar, disciplinar e fiscalizar o exercício da profissão de psicólogo e zelar pela fiel observância dos princípios da ética e da disciplina da classe. Conforme o princípio da supremacia do interesse público, deve fazê-lo de modo a proteger a coletividade de interesses individuais, seja dos profissionais fiscalizados, seja de dirigentes do Conselho. Não só a atuação profissional baseada em preceitos religiosos fere a laicidade, mas também feriria conceber a composição e o funcionamento do órgão de classe como uma arena para disputa de plataformas religiosas, pois colocaria interesses privados acima dos interesses coletivos, desviando o Conselho de suas finalidades institucionais e criando uma confusão inconstitucional e prejudicial, tanto à Administração Pública, quanto à própria liberdade de religião de todos aqueles que sejam derrotados no processo institucional da entidade.

Por fim, salienta-se que o conselho representa a defesa do interesse público sobre a atuação de quem exerce a profissão de psicólogo, e não a soma de interesses dos profissionais de estarem representados no conselho. Assim, não há que se falar em uma espécie de quota por representação para os psicólogos religiosos na composição do conselho, não sendo este argumento, portanto, cabível para autorizar a atuação do CFP baseada em preceitos religiosos. Como salientado na primeira parte desse artigo, não se pode confundir democracia laica pluriconfessional com fatiamento do Estado por denominações religiosas, muito menos como democracia das maiorias religiosas na esfera pública estatal. 


\section{Laicidade pluriconfessional, vida institucional e fiscalização do exercício profissional}

Assentadas as bases sobre a natureza jurídica do CFP, suas relações com a laicidade pluriconfessional e o regime jurídico-constitucional da Administração Pública, passa-se à análise do impacto sobre a sua organização, dinâmica institucional e deveres de fiscalização pelo CFP de modo mais detalhado. Além do conteúdo organizacional, o Conselho tem atribuições específicas de orientar, fiscalizar e disciplinar o exercício profissional e julgar as questões éticas dos seus membros.

Para fins didáticos e de forma a sistematizar o tema, apontam-se as regras jurídicas sobre tais atribuições. O dever de fiscalização do CFP está normatizado na Lei no 5.766/1971 (Brasil, 1971), regulamentada pelo Decreto no 79.822/1977 (Brasil, 1977). As atribuições de orientar, disciplinar e fiscalizar o exercício da profissão de Psicólogo estão previstas no artigo $6^{\circ}$, alínea $b$, da Lei no $5.766 / 1971$ e no artigo $6^{\circ}$, inciso IV, do Decreto $n^{\circ} 79.822 / 1977$. Nessa esteira, cabe ao Conselho a função de tribunal superior de ética profissional (art. $6^{\circ}$, alínea $f$, da Lei no ${ }^{\circ}$.766/1971; art. $6^{\circ}$, inciso VIII, do Decreto no ${ }^{\circ} 79.822 / 1977$ ), assim como a elaboração de Código de Ética Profissional (art. 6o alínea $e$, da Lei no 5.766/1971; art. 6º, inciso VII, do Decreto no 79.822/1977). Ainda há a atribuição de servir como órgão consultivo em matéria de Psicologia (art. $6^{\circ}$, alínea g, da Lei no 5.766/1971; art. $6^{\circ}$, inciso IX, do Decreto no 79.822/1977). Tais dispositivos representam a dinâmica institucional conjugada às atribuições basilares para a orientação, disciplinamento e fiscalização dos profissionais da Psicologia.

Para a aplicação legal das atribuições e deveres de fiscalização pelo CFP, a aprovação de um Código de Ética é medida adequada para a concretização das obrigações institucionais. A consolidação de um Código de Ética tem intuito normativo e regulatório da profissão. Além do escopo de reunir os princípios norteadores de um grupo profissional, serve como fundamento para a avaliação e julgamento das ações de tal grupo em relação à sociedade (Amendola, 2014). Pode-se dizer que há um duplo sentido: além de instituir um padrão ético de condutas, sujeição a punições e autorregulação profissional, também gera princípios profissionais aos prestadores do serviço regulado (Pereira, \& Pereira Neto, 2003).

Normalmente, os Códigos de Ética são criados através de resolução. Para a compreensão da natureza jurídica das resoluções, pode-se traçar um paralelo com as leis. Leis possuem cunho abstrato e genérico, sendo produzidas pelos Poderes Legislativos e denominadas leis em sentido formal. Já as resoluções são destinadas a casos concretos e situações individualizadas, dotadas de hierarquia inferior às leis (Streck, Sarlet, \& Clève, 2005) e emanadas, exemplificativamente, de pessoas jurídicas de direito público ou órgãos da administração pública. Nesse caso, o CFP, como autarquia, se enquadra como agente competente para a produção de resoluções. As resoluções são consideradas leis em sentido material, pois não são elaboradas pelos Poderes Legislativos (Marrara, 2014). Tanto as leis formais, gerais e abstratas (leis vindas do Legislativo), quanto as leis materiais (resoluções, por exemplo) são consideradas fontes de direito administrativo (Marrara, 2014), possuem força de lei e devem se submeter aos direitos fundamentais previstos na Constituição Federal.

Resoluções são limitadas em suas atividades reguladoras. Primeiro, há o limite impeditivo de expedição de regramentos gerais e abstratos, exclusivos das leis em sentido formal (Streck, Sarlet, \& Clève, 2005). No caso desse estudo, os limites do Código de Ética estão na Lei nº 5.766/1971. Segundo, à atividade resolutiva não é permitida a restrição de garantidas e direitos fundamentais, estando submetida aos princípios constitucionais (Streck, Sarlet, \& Clève, 2005).

No atinente à profissão de Psicólogo, antes do atual Código de Ética, houve a elaboração de outros estatutos $^{6}$. Em 2005, o vigente Código de Ética profissional dos psicólogos foi aprovado pelo CFP através da Resolução no 010/05 (Conselho Federal de Psicologia, 2005). Já em seu preâmbulo, se estabeleceu explicitamente a diretriz de respeito ao "disposto na Constituição Federal de 1988, conhecida como Constituição Cidadã, que consolida o Estado Democrático de Direito e legislações dela decorrentes". Com efeito, é possível afirmar que a dinâmica de fiscalização da atividade profissional estabelece a atenção aos princípios constitucionais, o que inclui a laicidade pluriconfessional, como já demonstrado. Inserir temas

\footnotetext{
${ }^{6}$ Sobre a história dos Códigos de Ética para os profissionais da Psicologia, ver Amendola (2014).
} 
como a laicidade pluriconfessional no âmbito da dinâmica interna das relações Psicólogo-Conselho e Psicólogo-Cliente, é de rigor, não só pelo seu conteúdo ético-profissional, também pelo atendimento à submissão dos quadros profissionais às normas jurídicas constitucionais em vigor.

A Apresentação do Código de Ética dos Psicólogos evidencia isso. Dentre valores guias para a prática da Psicologia, buscou-se um modelo de agir profissional ao reconhecimento social da categoria e além da mera normatização das atividades profissionais (CFP, 2005). O significado disso reflete na adoção de princípios em respeito a direitos fundamentais, como os advindos da Declaração Universal dos Direitos Humanos (CFP, 2005), estando assim previsto:

\section{PRINCÍPIOS FUNDAMENTAIS}

I. O psicólogo baseará o seu trabalho no respeito e na promoção da liberdade, da dignidade, da igualdade e da integridade do ser humano, apoiado nos valores que embasam a Declaração Universal dos Direitos Humanos.

II. O psicólogo trabalhará visando promover a saúde e a qualidade de vida das pessoas e das coletividades e contribuirá para a eliminação de quaisquer formas de negligência, discriminação, exploração, violência, crueldade e opressão (CFP, 2005).

A conduta do psicólogo com aporte em valores contidos na Declaração Universal de Direitos Humanos demonstra inegável relação entre o seu agir e a laicidade pluriconfessional. Assim, o respeito à igualdade e à liberdade é parte do próprio conteúdo e fundamento mesmo da laicidade para todos os indivíduos e grupos. Como visto na primeira parte, a laicidade atua na garantia da liberdade religiosa nas esferas pública e privada, o que implica não introduzir no exercício profissional conteúdos religiosos, sob pena de inviabilizar a atuação fiscalizatória e fragilizar sobremaneira o interesse público de todos na prestação de serviço psicológico fundado no conhecimento científico assente, o que se relaciona diretamente com preocupações de saúde pública.

Diante desse quadro, o exercício da profissão de psicólogo, a partir de uma perspectiva laica, não é uma opção pessoal; é um dever ético-profissional. A laicidade tem impacto nas políticas de saúde, o que inclui a atividade do psicólogo, e é pauta de agenda governamental de um Estado com bases democráticas (Diniz, 2013). É a compreensão de que "religião deve ser matéria de ética privada, e políticas públicas de saúde não devem ser fundamentadas em místicas religiosas sobre o bem-viver" (Diniz, 2013), o que, sem dúvida, implica a fiscalização profissional, como acima delineado ao mencionarmos o regime jurídico público regrador da atividade do CFP.

Nessa esteira, há os deveres previstos no Código de Ética, dentre os quais é possível destacar no que toca às responsabilidades do psicólogo:

Art. $1^{0}$ - São deveres fundamentais dos psicólogos $[\ldots]$

b) Assumir responsabilidades profissionais somente por atividades para as quais esteja capacitado pessoal, teórica e tecnicamente;

c) Prestar serviços psicológicos de qualidade, em condições de trabalho dignas e apropriadas à natureza desses serviços, utilizando princípios, conhecimentos e técnicas reconhecidamente fundamentados na ciência psicológica, na ética e na legislação profissional; [...]

Desse modo, as responsabilidades profissionais são informadas consoante as aludidas alíneas $b$ e $c$ do artigo $1^{\circ}$, isto é, ancoradas em capacidades técnicas e sob os fundamentos da ciência, ética e legislação. Daí os deveres de apartar as convicções religiosas e o exercício profissional; aquelas circunscritas à dimensão privada do psicólogo e este pautado em bases científicas compatíveis com a vivência democrática laica. A capacitação e a legitimidade profissionais não se coadunam com a propagação de convicções metafísicas ou com a disseminação de crenças religiosas.

Mais grave que amalgamar convicções religiosas privadas e exercício da Psicologia é transformar a prática profissional em oportunidade de discriminação, o que não poderia deixar de configurar ilícito ético-profissional expressamente previsto:

Art. $2^{\circ}$ - Ao psicólogo é vedado:

a) Praticar ou ser conivente com quaisquer atos que caracterizem negligência, discriminação, exploração, violência, crueldade ou opressão; 
b) Induzir a convicções políticas, filosóficas, morais, ideológicas, religiosas, de orientação sexual ou a qualquer tipo de preconceito, quando do exercício de suas funções profissionais; [...]

De fato, a atividade profissional que despreze a laicidade se arrisca fortemente a transformar-se em prática discriminatória ${ }^{7}$ advertência que também se aplica à vida institucional do CFP, acaso se distancie do conteúdo da laicidade constitucional. $\mathrm{O}$ atendimento sem razões científicas, baseado em convicções religiosas, tende à diferenciação, exclusão e restrição, sem considerar de modo igualitário aqueles que buscam tratamento psicológico. Do mesmo modo, organizar a vida institucional do Conselho a partir de plataformas e disputas religiosas fere igualmente a laicidade, na medida que estabeleceria um debate a partir de pontos de vista de fé, por definição impassível de crítica racional, a não ser dentro de uma específica e delimitada comunidade de fé.

Com efeito, malferida a laicidade, a prestação do serviço poderá gerar exclusão daqueles que não compartilhem da mesma fé ou tratamento desigual entre os que professam diferentes crenças. Nessa medida, na relação Psicólogo-Cliente, um profissional que não atenda aos princípios da laicidade violará as normas éticas e estará sujeito às penalidades previstas no Código de Ética da categoria.

Um exemplo concreto de não respeito à laicidade e consequências sociais antidemocráticas é o ativismo religioso neopentecostal no âmbito político (Campos, Gusmão, \& Maurício Júnior, 2015), culminado na apresentação de Projeto de Decreto Legislativo $n^{\circ}$ 234/2011, no qual se restringia a Resolução no 001/99 do Conselho Federal de Psicologia (1999). Na prática, a proposta viabilizaria tratamentos psicológicos de reversão da homossexualidade (Campos, Gusmão, \& Maurício Júnior, 2015), sintomaticamente defendido por figuras religiosas proeminentes, demonstrando quanto a violação da laicidade pode ter efeitos diretos na atividade profissional dos psicólogos.

O desrespeito à laicidade, assim concretizado, viola o Código de Ética e sujeita os infratores a consequências disciplinares, como as previstas no artigo 20 (penas de advertência, multa, censura pública e suspensão do exercício profissional por até 30 dias). Dependendo da prática concreta, ao se induzir convicções religiosas e a eventual configuração de discriminação, o ato pode ser considerado inclusive crime ${ }^{8}$, tendo efeitos jurídicos além dos julgamentos do órgão de classe, sem esquecer a responsabilidade civil por danos materiais e morais, bem como normas administrativas que restringem alvarás de funcionamento de estabelecimentos utilizados para a prática de atos discriminatórios ${ }^{9}$.

A observância do conteúdo democrático da laicidade constitucional, ancorada nos alicerces da liberdade de religião e da igualdade entre todos os cidadãos, a par de repercutir na vida institucional do CFP e na prática profissional dos psicólogos, amplia-se para além deste âmbito da fiscalização e do exercício profissionais, o que pode ser ilustrado diante de debates emblemáticos para a democracia na sociedade brasileira contemporânea, como se verá a seguir.

\section{Responsabilidade e tarefas do CFP na democracia laica pluriconfessional}

A laicidade constitucional pluriconfessional vai além das questões interna corporis e da relação entre o CFP e os profissionais da Psicologia. O conteúdo deste princípio se projeta também de modo decisivo na responsabilidade social e na interface do Conselho perante a sociedade como um todo, mormente considerando as diferenças e heterogeneidades presentes na sociedade (Holanda, 1997). De outro modo, estaria limitada a capacidade do cumprimento des-

\footnotetext{
${ }^{7}$ Conceito de Discriminação contido na Convenção Internacional sobre os Direitos das Pessoas com Deficiência, Decreto nº 6.949 (Brasil, 2009): "qualquer diferenciação, exclusão ou restrição baseada, com o propósito ou efeito de impedir ou impossibilitar o reconhecimento, o desfrute ou o exercício, em igualdade de oportunidades com as demais pessoas, de todos os direitos humanos e liberdades fundamentais nos âmbitos político, econômico, social, cultural, civil ou qualquer outro. Abrange todas as formas de discriminação, inclusive a recusa de adaptação razoável".

${ }^{8}$ Art. 20, Lei n ${ }^{\circ}$ 7.716/1989 (Brasil, 1989). Praticar, induzir ou incitar a discriminação ou preconceito de raça, cor, etnia, religião ou procedência nacional (Redação dada pela Lei no 9.459, de 15/05/97).

Pena: reclusão de um a três anos e multa (Redação dada pela Lei no 9.459, de 15/05/97). Crimes resultantes de preconceito de raça ou de cor (Brasil, 1989).

${ }^{9}$ Exemplo disso são as Leis Orgânicas de vários municípios brasileiros, tais como o artigo 150 da Lei Orgânica de Porto Alegre (Porto Alegre, 1990) e o artigo 119 da Lei Orgânica municipal de São Paulo (São Paulo, 1990).
} 
sas tarefas por parte do CFP e sua participação seria inadequada diante da sociedade e da construção da democracia. Ainda pior, corre-se o risco de uma interlocução conflitante com o pluralismo e diversidade reconhecidos e valorizados pela Constituição e pela sociedade democrática, na medida em que conteúdos religiosos específicos acabem por afirmar posturas discriminatórias por parte do CFP diante de debates importantes. Exemplos disso são as polêmicas sobre "cura gay", "ideologia de gênero" e "comunidades terapêuticas".

\section{“Cura gay"}

O Conselho Federal de Psicologia editou, em 1999, a Resolução no 01, que estabelece normas de atuação para os profissionais da Psicologia com relação à orientação sexual. Esta prevê, em respeito aos princípios éticos da profissão, especialmente os da não discriminação e da promoção do bem-estar das pessoas e da humanidade, que as(os) psicólogas(os) devem contribuir para o fim das estigmatizações e discriminações contra homossexuais. Ainda, proíbe práticas que venham a favorecer a patologização da homossexualidade, como é o caso dos tratamentos de cura.

Esta Resolução foi questionada pelo Projeto de Decreto Legislativo $n^{\circ} 234 / 2011$, por considerá-la limitação da atuação profissional que incorre em extrapolação do poder regulamentar e usurpação da competência do Poder Legislativo. O projeto foi proposto a fim de sustar a aplicação da resolução e de possibilitar tratamentos psicológicos "curativos" para a homossexualidade. Apesar de arquivado em 2013, a "cura gay" é defendida, sustentando que a liberdade profissional inclui o direito de atuação conforme valores e crenças religiosas e que o sofrimento vivenciado por homossexuais pode levar a mudanças de orientação sexual decorrentes da ajuda terapêutica.

Da perspectiva ora analisada, deve-se salientar que a atuação profissional não pode ser fundada em crenças religiosas. Em especial, quando tais convicções, além de contrárias ao conhecimento sedimentado na área, redundam na eleição da heterossexu- alidade como parâmetro de normalidade, tomando como patológicas e associando sofrimento às vivências da homossexualidade em si mesma. Isso sem esquecer que a imposição da heteronormatividade ${ }^{10}$ como forma privilegiada de exercício da sexualidade vai de encontro ao reconhecimento da diversidade e do reconhecimento dos direitos sexuais, na contramão dos direitos fundamentais da liberdade, da dignidade e da igualdade sexuais ${ }^{11}$.

Também é importante deixar claro que afirmar a incompatibilidade da "cura gay" com o dever de laicidade nada tem a ver com negativa de tratamento a indivíduos em sofrimento. Ao contrário, trata-se de afastar do exercício da Psicologia concepções preconceituosas que naturalizam o sofrimento em tantos casos provocado pela homofobia e que tomam os privilégios e a violência da heteronormatividade como se fossem um dado científico.

A heteronormatividade compulsória, equivocadamente invocada de modo associado à liberdade de religião no exercício profissional, acabaria por criar uma cidadania de segunda classe àqueles dela dissonantes, em flagrante e direta violação do mandamento constitucional antidiscriminatório, ínsito aos princípios éticos que se relacionam ao exercício da Psicologia.

Importante ressaltar que, como todo e qualquer direito, a liberdade no exercício da profissão não é absoluta, ou seja, não se trata de um salvo conduto para as(os) profissionais atuarem da forma como lhes convêm. Pelo contrário, as profissões são regulamentadas por lei federal conforme a Constituição que consagra a democracia laica. Nesse campo, não há espaço para o influxo de crenças religiosas, cujo conteúdo por definição não está sujeito ao escrutínio e debate público racional e controlável, o que tornaria o exercício da Psicologia de impossível regulação e fiscalização e abriria espaço até mesmo para o charlatanismo.

\section{"Ideologia de gênero"}

Relacionadas à polêmica sobre a "cura gay", as iniciativas pela proibição daquilo que por alguns é detratado como "ideologia de gênero" também recla-

\footnotetext{
${ }^{10}$ Compreende-se heteronormatividade como a ordem social em que as demandas, expectativas e obrigações sociais derivam do pressuposto da heterossexualidade como natural e, portanto, como fundamento da sociedade (Miskolci, 2009).

${ }^{11}$ Sobre a decisão do Supremo Tribunal Federal, na qual são expressamente afirmados tais direitos sexuais relacionados à orientação sexual, ver Rios (2011).
} 
mam reflexão pelo CFP. Essa contribuição, para estar à altura dos deveres democráticos ínsitos ao regime jurídico ao qual se submete o Conselho, não pode afastar-se do conteúdo da laicidade constitucional, sob pena de violação da valorização constitucional do pluralismo social.

Nesse quadro, é necessário observar do conteúdo da laicidade democrática significa distanciar-se de todo e qualquer argumento ou profissão de fé religiosa, sem o que, como visto, a liberdade de religião e a igualdade de todos ficam comprometidas.

Desse modo, do ponto de vista jurídico-constitucional, em especial considerando o princípio organizativo da atividade estatal da laicidade, o que se requer é a ausência de motivações e objetivos religiosos na reflexão e na contribuição por parte do CFP nesse debate. Sem atenção à laicidade, será praticamente inviável ao CFP dar conta dessa tarefa que lhe cabe, devido à expertise específica que carrega, dado o desafio constante trazido pela origem e presença religiosa nessas iniciativas ${ }^{12}$. Tudo sem descuidar que a utilização da entidade orientada por diretrizes ou impulsos religiosos configuraria, do ponto de vista jurídico, desvio de finalidade institucional.

\section{"Políticas públicas de saúde" e credenciamento de cursos}

Além de apresentar-se diante de questões específicas, a laicidade como princípio jurídico de observância obrigatória alcança esfera mais ampla, incidindo sobre a contribuição e a participação que o CFP ofereça para a formulação e aplicação das políticas públicas em geral, e, em especial, na área da saúde e dos direitos sexuais e reprodutivos.

Com efeito, definidas como conjuntos de disposições, medidas e procedimentos que traduzem a orientação política do Estado e regulam as atividades governamentais relacionadas às tarefas de interesse público, as políticas públicas englobam tanto as ações de governo, tomadas pela Administração direta e indireta, quanto atividades de regulação de outros agentes sociais e econômicos ${ }^{13}$.

O Decreto no 5.773/2006 (Brasil, 2006) prevê as regras de credenciamento, autorização e reconhe- cimento de cursos superiores pelo Ministério da Educação. No artigo $28, \S 2^{\circ}$ há a previsão de que a criação de cursos de graduação em Psicologia deverá ser submetida à manifestação do Conselho Nacional de Saúde (CNS). Nessa esteira, a Resolução $n^{\circ} 429 / 2009$ do CNS (Brasil, 2009b), para os fins do artigo $28,2^{\circ}$, estabeleceu a prerrogativa de análise dos processos autorizadores de cursos superiores lá previstos à Comissão Intersetorial de Recursos Humanos (CIRH/CNS). A estrutura da CIRH/CNS é composta de representantes institucionais condizentes com as competências estabelecidas pela comissão, de acordo com o previsto na Resolução $n^{\circ}$ 496/2014 do CNS (Brasil, 2014). Assim, o Conselho Federal de Psicologia figura como membro da CIRH/CNS, conforme o artigo $1^{\circ}, \mathrm{I}, 16$, da resolução, tendo influência direta, a partir de sua manifestação, para a autorização e credenciamento de cursos de Psicologia no Brasil. Diante de mais esta atribuição, a atenção à laicidade constitucional como princípio organizativo da esfera estatal se mostra necessária como princípio norteador da atuação institucional do CFP.

Nesse campo, a laicidade como princípio de organização da vida estatal toma corpo vigoroso, na medida em que proscreve a mistura entre conteúdos e argumentos racionais, passíveis de crítica, debate e deliberação públicos, acessíveis a todos os participantes, e aqueles próprios de fé religiosa, cujas legítimas manifestações reservam-se às respectivas comunidades confessionais.

Nesse sentido, pode-se concluir que não há espaço para atividades institucionais e profissionais que incorram nessa confusão, ficando sem sentido adjetivações tais quais "Psicologia cristã", "Psicologia budista", "Psicologia islâmica", "Psicologia hindu" ou equivalentes, sempre que queiram expressar um saber, técnica ou procedimentos psicológicos orientados religiosamente. Tal cuidado, todavia, não pode ser mal compreendido como proibição do exercício profissional por crentes de determinada religião, mas sim dever ético de não fundir tais dimensões, o que redundaria em enfraquecimento e prejuízo tanto da liberdade de religião, quanto da prática profissional e do desenvolvimento do conhecimento científico.

\footnotetext{
${ }^{12}$ Nesse sentido, ver iniciativas religiosas como Oliveira (2015).

${ }^{13}$ Definição de Lucchese (2004).
} 
Em mesmo sentido, a atuação institucional deve observar, no exercício de atribuições e competências próprias, tais como o credenciamento de cursos e o reconhecimento de especialidades técnico-profissionais (Conselho Federal de Psicoogia, 2007), a laicidade constitucional como princípio organizativo da esfera estatal. Do mesmo modo que ocorre com o exercício profissional aludido no parágrafo anterior, cursos e especialidades objetivando estabelecer bases religiosas para a atuação profissional configuram violação à laicidade, por comprometer os direitos fundamentais dos quais ela emana e tornarem inviável não só o desenvolvimento do conhecimento científico, mas também a própria missão institucional do Conselho.

\section{Considerações finais}

A laicidade, princípio democrático de organização da vida política estatal, tem seus alicerces nos direitos da liberdade de religião e da igualdade. Seu conteúdo informa todos os órgãos estatais, cuja mis- são é proteger o interesse público e efetivar o exercício dos direitos humanos.

Esse componente institucional é especialmente importante na dinâmica organizacional e na atividade desempenhada por Conselhos que congregam expertise e profissionais cuja atuação na saúde pública defronta-se com intensa polêmica decorrente do pluralismo e da diversidade. Ele se torna ainda mais necessário quando a democracia é confrontada por projetos de poder que apostam na mobilização de crenças religiosas como instrumento de pressão na vida política estatal. Desafio este agravado pelo perigo da manipulação da laicidade pluriconfessional, ora mal compreendida, ora distorcida.

Nesse contexto, mais do nunca se faz necessário afirmar a prevalência da laicidade como princípio organizador da vida institucional do Conselho Federal de Psicologia e como diretriz informadora não só da atividade de fiscalização do exercício profissional da entidade, mas também da contribuição que a sociedade brasileira dele espera para a concretização da vida democrática.

\section{Referências}

Amendola, M. F (2014). História da construção do Código de Ética Profissional do Psicólogo. Estudose Pesquisas em Psicologia, 14(2), 660-685. Recuperado de http://www.e-publicacoes.uerj.br/index.php/revispsi/article/view/12559/9743

Blancarte, R. (2008). O porquê de um Estado laico. In R. A. Lorea (Org.), Em defesa das liberdades laicas. Porto Alegre, RS: Livraria do Advogado.

Bobbio, N. (1999). Cultura laica y laicismo. La Onda Digital. Recuperado de http://www.laondadigital.uy/ LaOnda2/001-100/38/Cultura\%20laica\%20y\%20laicismo.htm

Bobbio, N., Mateucci, N., \& Pasquino, G. (1986). Dicionário de política. (C. C. Varrialle, G. L. Mônaco, J. Ferreira, L. G. P. Cacais, \& R. Dini, Trads.). Brasília, DF: UnB.

Brasil. (2011b). Câmara dos Deputados. Projeto de Decreto Legislativo PDC 232/2011, de 1 de junho de 2011. Dispõe sobre a convocação de plebiscito para decidir sobre a união civil de pessoas do mesmo sexo; respondendo a seguinte questão: “Você é a favor ou contra a união civil de pessoas do mesmo sexo?". Recuperado de http:// www.camara.gov.br/proposicoesWeb/ fichadetramitacao?idProposicao=505224

Brasil. (2011a). Câmara dos Deputados. Proposta de Emenda à Constituição No 99, de 2011 (Do Sr João Campos e outros. Acrescenta ao art. 103, da Constituição Federal, o inc. X, que dispõe sobre a capacidade postulatória das Associações Religiosas para propor ação de inconstitucionalidade e ação declaratória de constitucionalidade de leis ou atos normativos, perante a Constituição Federal.

Recuperado dehttp://www.camara.gov.br/proposicoesWeb/prop_mostrarintegra;jsessionid=21E07D0878A575D7918AE509816F3E5B.nodel?codteor=931483\&filename=PEC+99/2011

Brasil. (1988a). Constituição da República Federativa do Brasil. Brasília, DF: Senado Federal.

Brasil. (2006). Decreto No 5.773, de 9 de maio de 2006. Dispõe sobre o exercício das funções de regulação, supervisão e avaliação de instituições de educação superior e cursos superiores de graduação e seqüenciais no sistema federal de ensino. Diário Oficial da União, 10 de maio.

Brasil. (2009a). Decreto № 6.949, de 25 de agosto de 2009. Promulga a Convenção Internacional sobre os Direitos das Pessoas com Deficiência e seu Protocolo Facultativo, assinados em Nova York, em 30 de março de 2007. Diário Oficial da União, 26 de agosto. 
Brasil. (1977). Decreto No 79.822, de 17 de junho de 1977. Regulamenta a Lei no 5.766, de 20 de dezembro de 1971, que criou o Conselho Federal e os Conselhos Regionais de Psicologia e dá outras providências. Diário Oficial da União, 20 de junho.

Brasil. (1971). Lei № 5.766, de 20 de dezembro 1971. Cria o Conselho Federal e os Conselhos Regionais de Psicologia e dá outras providências. Diário Oficial da União, 20 de dezembro.

Brasil. (1989). Lei No 7.716, de 5 de janeiro de 1989. Define os crimes resultantes de preconceito de raça ou de cor. Diário Oficial da União, 9 de janeiro.

Brasil. (1998). Lei No 9.649, de 27 de maio de 1998. Dispõe sobre a organização da Presidência da República e dos Ministérios, e dá outras providências. Diário Oficial da União, 5 de junho.

Brasil. (1999). Lei № 9.784, de 29 de janeiro de 1999. Regula o processo administrativo no âmbito da Administração Pública Federal. Diário Oficial da União, 11 de março.

Brasil (2009b). Ministério da Saúde. Conselho Nacional de Saúde. Resolução No 429, de 12 de novembro de 2009. [Reafirma o entendimento de que cabe à Comissão Intersetorial de Recursos Humanos - CIRH/CNS a prerrogativa de analisar os processos de autorização de oferta de cursos superiores]. Recuperado de http://bvsms.saude. gov.br/bvs/saudelegis/cns/2009/res0429_12_11_2009.html

Brasil (2014). Ministério da Saúde. Conselho Nacional de Saúde. Resolução № 496, de 8 de maio de 2014. [Aprova a Reestruturação da Comissão Intersetorial de Recursos Humanos - CIRH]. Recuperado de http://bvsms.saude. gov.br/bvs/saudelegis/cns/2014/res0496_08_05_2014.html

Cady, L., \& Hurd, E. S. (2010). Comparative secularism and the politics of modernity: an introduction. In L. Cady, \& E. S. Hurd (Orgs.), Comparative secularism in a global age (pp. 3-24). New York, NY: Palgrave Macmillan.

Campos, R. B. C., Gusmão, E. H. A., \& Mauricio Júnior, C. G. B. (2015). A disputa pela laicidade: uma análise das interações discursivas entre Jean Wyllys e Silas Malafaia. Religião \& Sociedade, 35(2), 165-188. https:// doi.org/10.1590/0100-85872015v35n2cap07

Canotilho, J. J. G. (2003). Direito constitucional e teoria da constituição (7a ed.). Coimbra: Almedina.

Conselho Federal de Psicologia - CFP. (1999). Resolução CFP No 01/99, de 22 de março de 1999. Estabelece normas de atuação para os psicólogos em relação à questão da orientação sexual. No. Recuperado de http://site.cfp.org. br/wp-content/uploads/1999/03/resolucao1999_1.pdf

Conselho Federal de Psicologia - CFP. (2005). Resolução No 010/05. Aprova o Código de Ética Profissional do Psicólogo. Recuperado de http://site.cfp.org.br/wp-content/uploads/2005/07/resolucao2005_10.pdf

Conselho Federal de Psicologia - CFP. (2007). Resolução No 013/2007. Institui a Consolidação das Resoluções relativas ao Título Profissional de Especialista em Psicologia e dispõe sobre normas e procedimentos para seu registro. Recuperado de http://site.cfp.org.br/wp-content/uploads/2007/09/resolucao2007_13.pdf

Cunha, C. (2012). Religião e política: uma análise da atuação de parlamentares evangélicos sobre direitos das mulheres e de LGBTs no Brasil. Rio de Janeiro, RJ: Fundação Heinrich Boll.

Di Pietro, M. S. Z. (2014). Direito administrativo (27a ed.). São Paulo, SP: Atlas.

Diniz, D. (2006). Quando a verdade é posta em dúvida. In D. Diniz, S. Buglione, \& R. R. Rios (Orgs.), Entre a dúvida e o dogma: liberdade de cátedra e universidades confessionais no Brasil. Porto Alegre, RS: Livraria do Advogado.

Diniz, D. (2013). Estado laico, objeção de consciência e políticas de saúde. Cadernos de Saúde Pública, 29(9), 1704-1706. https://doi.org/10.1590/0102-311XPE010913

Duarte, L. F. D. (Org.). (2009). Valores religiosos e legislação no Brasil: a tramitação de projetos de lei sobre temas morais controversos. Rio de Janeiro, RJ: Garamond.

Giumbelli, E. (2012). Minorias e religiosidade em seus contextos. In A. C. S. Lima (Org.), Antropologia e direito: temas antropológicos para estudos jurídicos (pp. 240-245). Brasília, DF: Associação Brasileira de Antropologia.

Holanda, A. (1997). Os Conselhos de Psicologia, a formação profissional e o exercício profissional. Psicologia: Ciência e Profissão, 17(1), 3-13. https://doi.org/10.1590/S1414-98931997000100002

Huaco, M. (2008). A laicidade como princípio constitucional do Estado de Direito. In R. A. Lorea (Org.), Em defesa das liberdades laicas. Porto Alegre, RS: Livraria do Advogado. 
Psicologia: Ciência e Profissão Jan/Mar. 2017 v. 37 nº 1, 159-175.

Keane, J. (2000). Secularism? The Political Quarterly, 71(Suppl s1), 5-19. https://doi.org/10.1111/1467-923X.71.s1.3

Lopes, J. R. L., \& Vilhena, O. (2013). Religiões e direitos humanos. Jornal O Estado de São Paulo. Recuperado de http://opiniao.estadao.com.br/noticias/geral,religiao-e-direitos-humanos-imp-,1023910

Lorea, R. A. (2008). O assédio religioso. In R. A. Lorea (Org.), Em defesa das liberdades laicas. Porto Alegre, RJ: Livraria do Advogado.

Lucchese, P. (2004). Políticas públicas em Saúde Pública. São Paulo: Centro Latino-Americano e do Caribe de Informação em Ciências da Saúde.

Marrara, T. (2014). As fontes do direito administrativo e o princípio da legalidade. Revista Digital de Direito Administrativo, 1(1), 23-51. https://doi.org/10.11606/issn.2319-0558.vlilp23-51

Mello, C. A. (2012). Curso de direito administrativo (30a ed). São Paulo, SP: Malheiros.

Miskolci, R. (2009). A Teoria Queer e a sociologia: o desafio de uma analítica da normalização. Sociologias, (21), 150-182. https:// doi.org/10.1590/S1517-45222009000100008

Morin, E., \& Ramadan, T. (2014). Au péril des idées: les grandes questions de notre temps. Paris: Chatelet.

Oliveira, E. C. (2015). Ideologia de gênero: perniciosa perseguição religiosa. São Paulo: Instituto Plinio Corrêa de Oliveira.

Oro, A. P. (2008). A laicidade na América Latina: uma apreciação antropológica. In R. A. Lorea (Org.), Em defesa das liberdades laicas. Porto Alegre, RS: Livraria do Advogado.

Oro, A. P., \& Ureta, M. (2007). Religião e política na América Latina: uma análise da legislação dos países. Horizontes Antropológicos, 13(27), 281-310. https://doi.org/10.1590/S0104-71832007000100013

Pereira, E. (2013). Poder e medo: os evangélicos na política e o combate à agenda feminista no Brasil. Religião \& Sociedade, 33(1), 199-203. https://doi.org/10.1590/S0100-85872013000100011

Pereira, F. M., \& Pereira Neto, A. (2003). O psicólogo no Brasil: notas sobre seu processo de profissionalização. Psicologia em Estudo, 8(2), 19-27. https:// doi.org/10.1590/S1413-73722003000200003

Pierucci, A. F., \& Prandi, R. (1996). A realidade social das religiões no Brasil:religião, sociedade e política. São Paulo: Hucitec.

Pinheiro, D. A. R. (2008). Direito, estado e religião: a constituinte de 1987/1988 e a (re)construção da identidade religiosa do sujeito constitucional brasileiro. Belo Horizonte, MG: Argumentum.

Porto Alegre. (1990). Lei No 0/1990, de 3 de abril de 1990. Lei Orgânica do Município de Porto Alegre. Diário Oficial do Município, 4 de abril.

Rios, R. R. (2015). A laicidade e os desafios à democracia no Brasil: neutralidade e pluriconfessionalidade na constituição de 1988. In H. C. Nardi, P. S. Machado, \& R. S. Silveira (Orgs.), Diversidade sexual e relações de gênero nas políticas públicas: o que a laicidade tem a ver com isso? (pp. 17-38). Porto Alegre, RS: Deriva/ Abrapso.

Rios, R. R. (2011). Direitos sexuais, uniões homossexuais e a decisão do Supremo Tribunal Federal (ADPF n. 132-RJ e ADI 4.277). In R. R. Rios, C. Golin, \& P. G. C. Leivas (Orgs.), Homossexualidade e direitos sexuais: reflexões a partir da decisão do STF (pp. 69-114). Porto Alegre, RS: Sulina.

Sabet, A. (2008). Islam and the political. London: Pluto.

São Paulo (Município). (1990). Lei orgânica do Município de São Paulo. Recuperado de http://www.tcm.sp.gov.br/ legislacao/lomun/lom_tl.htm

Sarmento, D. (2008). O crucifixo nos tribunais e a laicidade do estado. In R. A. Lorea (Org.), Em defesa das liberdades laicas. Porto Alegre, RS: Livraria do Advogado.

Streck, L. L., Sarlet, I. W., \& Clève, C. M. (2005). Os limites constitucionais das resoluções no Conselho Nacional de Justiça (CNJ) e Conselho Nacional do Ministério Público (CNMP). Revista do ESMESC, 12(18), 15-24. Recuperado de http://www.egov.ufsc.br/portal/sites/default/files/anexos/15653-15654-1-PB.pdf

Vier, F. Constituição "Dei Verbum”. (1984a). Compêndio do Vaticano II: constituições, decretos, declarações (pp. 119-140). Petrópolis, RJ: Vozes.

Vier, F. Constituição "Gaudium et Spes". (1984b). Compêndio do Vaticano II: constituições, decretos, declarações (pp. 141-256). Petrópolis: Editora Vozes. 
Wohlarb-Sahr, M., \& Burchardt, M. (2012). Multiple secularities: toward a cultural sociology of secular modernities. Comparative Sociology, 11(6), 875-909. https:// doi.org/10.1163/15691330-12341249

Zylbersztajn, J. (2012). O princípio da laicidade na Constituição Federal de 1988 (Tese de doutorado). Faculdade de Direito da Universidade de São Paulo, São Paulo.

\section{Roger Raupp Rios}

Doutor em Direito pela Universidade Federal do Rio Grande do Sul, Porto Alegre - RS. Pós-Doutor em Direito pela Université Paris II, Paris. França. Docente da UniRitter, Porto Alegre - RS. Brasil.

E-mail: roger.raupp.rios@gmail.com

\section{Alice Hertzog Resadori}

Doutoranda em Direito pela UFRGS, Mestre em Direito pela UniRitter, Porto Alegre - RS. Brasil.

E-mail: ali.resadori@gmail.com

\section{Rodrigo da Silva}

Mestre em Direito pela UniRitter, Porto Alegre - RS. Brasil.

E-mail: rodrigodsilva@hotmail.com

\section{Daniel Martins Vidor}

Mestrando em Direito pela UniRitter, Porto Alegre - RS. Brasil.

E-mail: daniel.vidor@gmail.com

Endereço para envio de correspondência:

Foro da Justiça Federal, $4^{\text {a }}$ Vara Federal de Porto Alegre.

Rua Otávio Francisco Caruso da Rocha 600 - $6^{\circ}$ andar

Centro. CEP: 90010-395.

Porto Alegre - RS. Brasil.

Recebido 17/07/2016

Aprovado 13/12/2016

Received $07 / 17 / 2016$

Approved 12/13/2016

Recibido $17 / 07 / 2016$

Aceptado 13/12/2016

Como citar: Rios, R. R., Resadori, A. H., Silva, R., \&Vidor, D. M. (2017). Laicidade e Conselho Federal de Psicologia: dinâmica institucional e profissional em perspectiva jurídica. Psicologia: Ciência e Profissão, 37(1): 159-175.

https://doi.org/10.1590/1982-3703002612016

How to cite: Rios, R. R., Resadori, A. H., Silva, R., \& Vidor, D. M. (2017). Laicity and CFP: institutional and professional dynamics in legal perspective. Psicologia: Ciência e Profissão, 37(1): 159-175.

https://doi.org/10.1590/1982-3703002612016

Cómo citar: Rios, R. R., Resadori, A. H., Silva, R., \& Vidor, D. M. (2017). Secularismo y el CFP: dinámica institucional y profesional en perspectiva jurídica. Psicologia: Ciência e Profissão, 37(1): 159-175.

https://doi.org/10.1590/1982-3703002612016 